\title{
COMMENTARY
}

\section{Let us go forth and safely multiply}

\section{Synthetic biology, which involves the engineering of new biological components and organisms and the redesign of existing ones, will require community discipline and openness if it is to flourish safely, says George Church.}

\rceil he developing field of 'synthetic biology' could be seen as yet another expression of scientific hubris. It has potential benefits, such as the development of low-cost drugs or the production of chemicals and energy by engineered bacteria. But it also carries risks: manufactured bioweapons ${ }^{1}$ and dangerous organisms could be created, deliberately or by accident.

There is now a short window of opportunity during which the neologism can be attached to novel unions between the existing fields of genetic engineering, synthetic chemistry and metabolic engineering. Synthetic biology also needs to distinguish itself as a safe community effort that nurtures responsible practices and attitudes. For some, synthetic biology shares the potential, along with nanotechnology and artificial intelligence, to generate new entities that can reproduce and evolve at will ${ }^{2,3}$. Whether we believe that these are immediate, distant or imaginary threats, the concerns are real. For their part, biologists are excited by the potential for manufacturing precise, reliable and scalable synthetic components.

\section{Safety first}

A code of ethics and standards should emerge for biological engineering as it has done for other engineering disciplines. The community recognizes this need, but discussions are fragmentary. The next international meeting on synthetic biology (in May 2006 at the University of California, Berkeley) should make significant progress in that direction. What practical guidelines ought to be considered?

First, proper use of physical-isolation measures, as is already prescribed by levels 2 to 4 of the biosafety laboratory standards. Level 2 requires biological safety cabinets, lab coats, gloves and face protection; level 4 specifies a separate building, full-body suits and more.

Second, biological isolation - engineering biological systems to reduce their viability outside the lab and factory - should become standard practice. Genetic strains can be designed to require essential nutrients that are unavailable in the wild. The genome can also be engineered so that the genes cannot function in other cells. For example, a sufficiently novel genetic code for protein synthesis, not based on the standard amino-acid code, would not be expressed or function properly if taken up by natural cells or viruses. These safeguards should prevent genes for new toxins, allergens or pathogens from mixing and stably recombining with wild species.

The list of precautions is limited only by our creativity. Engineered cells could be programmed to self-destruct after a fixed time or on detecting an external signal. Similarly, engineered sequences can act as 'watermarks' for easier tracking. Genetic sequences that move around easily, such as transposons, can be removed from cells, thereby reducing undesirable genetic changes ${ }^{4}$. Other safety features we can imagine go beyond single-

"Learning from gene therapy,

we should imagine worst-case

$$
\text { scenarios and protect }
$$

\section{against them."}

gene manipulations associated with conventional genetic engineering. For example, useful industrial microbes could be designed to have reduced mutation rates, except under specific lab conditions. Other microbes could be modified to detect the production of undesirable chemicals.

We should encourage young scientists to think constructively and build environments for sharing biological resources, with an emphasis on safety, as is happening in the International Genetically Engineered Machine (iGEM) programme. This event involves a growing number of universities (13 this year) sponsoring students to construct synthetic genetic systems (see page 417).

Above all, outreach is required. Genetically modified products, including crops and genetherapy drugs, have been opposed for reasons that go beyond worries about scientific uncertainties. Cítizens who will gladly take recombinant-DNA drugs (such as interferon, insulin and erythropoietin) are reluctant to eat foods containing even trace amounts of recombinant DNA. Can synthetic biology gain greater public trust? We should learn from past cases, in the case of foods generated by synthetic biology, for example, we need to recognize that stakeholders include not just the farmers, but their neighbours and grocery shoppers also.

Learning from gene therapy, we should imagine worst-case scenarios and protect against them. For example, full physical isolation and confined lab experiments on human or agricultural pathogens should continue until we have data on a greater number of potential consequences - ecological and medical - of engineering such systems. Moving from dosed-lab commercial projects to open-air systems will require appropriate experimental procedures and perhaps higher levels of biological isolation.

\section{A watchful eye}

In addition to a code of professional ethics for synthetic biologists, we need to watch for the rare cases when they transgress. This requires not just laws, but also monitoring compliance ${ }^{5}$. This could exploit government experience in the surveillance of illegal drugs and hazardous materials. In the commercial sector, monitoring systems could reveal suspect activities, such as labs requesting DNA that is related to potentially harmful biological agents. The purchase of precursor chemicals, nudeic acids, genes and designer cells could be screened against a pathogen database. However, automated monitoring will require cooperation by manufacturers $^{6}$ and international coordination. Discussions about this have begun, induding one funded by the Sloan Foundation? ${ }^{7}$. But any actions that penalize the legitimate manufacturer or user are likely to backfire, and having laws without government-mandated surveillance will be ineffective.

Finally, the community needs to discuss the benefits of synthetic engineering to balance the necessary, but distracting, focus on risks. From now on, each small step towards engineering enzymatic pathways for cheaper pharmaceuticals, smart biomaterials and large-scale integrated genetic circuits should be celebrated.

George Church is in the Department of Genetics, Harvard Medical School, 77 Avenue Louis Pasteur, Boston, Massachusetts 02115, USA.

1. Alibek, K. Biahazard (Delta, New York, 1999).

2. Joy, B. www.wired.com/wired/archive/8.04/joy_pr.html (2000).

3. Kurrweil, R. The Singularity is Near. When Humans Transcend Bialogy (Viking New York, 2005).

4. Kolisnychenka V.etal Genome Res 12, 640-647(2002)

5. Church, G.M.Synthetic Cell Projects http://arep.med harvardedu/SBP/ (2004)

6. Aldhous, P. New Scientistmagazine 188 (2525), 8 (2005)

7. Study to explare risks, benefits of synthetic genomics http://webmitedu/newsoffice/2005/5yntheticbiohtml (2005). 